Dhaka Univ. J. Biol. Sci. 28(1): 61-69, 2019 (January)

\title{
MEDIUM-TERM EFFECT OF EARLY LIFE WEATHER SHOCK ON NON-VERBAL INTELLIGENCE OF SIDR AFFECTED CHILDREN
}

\author{
Osman Goni, Mollika Roy, Nasreen Wadud and Arobindu Dash ${ }^{* 1}$ \\ Department of Psychology, University of Dhaka, Dhaka-1000, Bangladesh
}

Key words: Early life stress, Weather shock, Medium-term effect, Non-verbal intelligence

\begin{abstract}
The present study intends to investigate the medium-term effect of early life weather shock on non-verbal intelligence of SIDR affected children. The hypothesis was, the nonverbal IQ of SIDR affected children would be lower than the non-verbal IQ of SIDR non-affected children. For this purpose, 60 students of grade 4 - 5 were selected as respondents. Among them half of the respondents were from SIDR affected area and remaining were from non-affected area. In order to measure non-verbal intelligence, Test of Non-verbal Intelligence-2 (TONI-2) was administered which was developed by Brown et al. (1990). Independent-sample $t$-test was employed to compare the non-verbal intelligence of the participants in SIDR affected and SIDR non-affected conditions. The result shown that there is a significant difference on non-verbal intelligence between affected and non-affected samples and the nonverbal intelligence (IQ) of SIDR affected children is significantly lower than the non-verbal intelligence (IQ) of non-affected participants.
\end{abstract}

\section{Introduction}

In a child's life, early childhood is a very critical period that extends from birth to five years old ${ }^{(1)}$. In this age period, early life stress may be positive, tolerable or toxic. When experiences are prolonged in terms of intensity and duration, 'toxic stress' can occur $^{(2)}$. These may arise from internal or external stressors. External stressors comprise many aspects of our lives including natural disasters. Because of that the development of our brain functioning may be threatened and cause negative impact ${ }^{(3)}$. Rapid cognitive, linguistic, social, emotional, and motor developments occur during the period between birth and three years. These qualities are evident to be robust predictors of later schooling as well as life success ${ }^{(4)}$. Every year, more than 100 million children are gone through disasters ${ }^{(5)}$. Any natural calamity has large-scale, sole episode potentially traumatic events. At the same time, reality is that natural disasters are increasing in intensity and frequency(6). Several research findings found that disasters produce a significant threat to children's mental health ${ }^{(7)}$ at the same time, women and children are much more vulnerable in any natural disasters ${ }^{(8)}$. Non-verbal intelligence development is

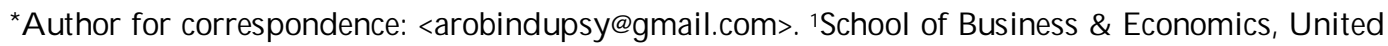
International University, Dhaka-1212, Bangladesh. 
one of the primary presenting problems in children after disasters ${ }^{(9)}$ and this deficiency may be increased if proper steps are not taken adequately and comprehensively ${ }^{(10)}$.

Weather shock in early life causes various stressful experiences such as parental death or injuries, death of close relatives, malnutrition, economic crisis, epidemics of various infectious diseases etc. Weather shock includes cyclone, excessive rain fall, drought, flood etc. In the evening of 15 November 2007, cyclone SIDR smashed the south-western coast of Bangladesh. It was a category-4 super cyclone with peak winds 250 kilometers per hour. In April 2009, a moderate cyclone BIJLI occurred. It could not cause much devastation with the exemption of certain minor damage. While a subsequent cyclone AILA had caused major devastation in some previously SIDR affected localities which also hampered the actions of SIDR recovery programs for a few months. After such type of cyclone or hurricane, children's nourishment had faced a significant threat, while adult's consumption was not affected in a large-scale(11). Several NGOs had already conducted several studies for investigating the psychosocial impacts of SIDR among the fishermen (fear of returning to the sea), the aged and children community who lost their caregivers or parents. On the basis of CARE (Cooperative for Assistance and Relief Everywhere) report, many children lost either one or both parents in Borguna, Southkali and Patharghata(12). The phrase 'medium-term' is widely used in economic literature. Aguilar et al.(13) measured medium-term effect (after four to five years) of the children's cognitive and health outcomes following any weather shock.

Cognitive development in childhood starts from birth and continues till 16 years of life ${ }^{(14)}$. Cognitive skills are largely stable after 10 years of age, while some evidence shows easier remediation for lack of social abilities ${ }^{(15)}$. Any traumatic experience in this time period may affect cognitive development especially development of intelligence ${ }^{(16)}$. It is stated that in case of intelligence, genetic domination is $20 \%$ and the rest $80 \%$ is environmental ${ }^{(17)}$. So, our surroundings (including natural calamities) broadly affect our intellectual skills development and its functioning.

It is impossible to define intelligence in a single term because it is not limited to only abstract thought, problem solving, emotional stability, self-awareness, understanding, reasoning and communication. There have some correlates that influence to develop intelligence such as home, environmental enrichment, nutrition, stress, parents' socioeconomic status etc.(18). Intelligence test scores depend on the accessibility to resources of home and stimulating learning home environment ${ }^{(19)}$. Traumatic events especially 'PostTraumatic Stress Disorder' (PTSD) are negatively related with IQ scores of children and adults(21). Hanscombe et al.(22) found that intelligence level in lower-socio-economic status families are relatively low enough and in contrast, the evidences of genetics $x$ environment interaction are minimal. They also found the environmental effect on intelligence rather than genetic effect in the moderation study. To measure intelligence psychologists use intelligence test. There are two types of intelligence test on the basis of 
using words or not using words- verbal intelligence test and non-verbal intelligence test. Non-verbal intelligence tests include abstract figural problem solving. Here, we measured intelligence scores by administering Test of Non-verbal Intelligence-2, TONI-2(23).

Both health scientists and economists have paid more interest in recent years to study the impact of early-life conditions on later-life outcomes. Their focuses are different. Health scientists' focal point is to identify the impact of early childhood growth and environmental conditions on the later-life health outcomes. Psychologist as a health scientist, our present study investigates the medium-term impacts of damaging event experienced during early childhood phases of life on children's IQ. A remarkable criterion of the present study was that the participants of the present study were exposed to SIDR at 4 - 5 years of age. Most of the previous research studies focused on first 3 years of life ${ }^{(24)}$. While, during the age of 4 - 5 years children's social context becomes more important. Their reasoning ability and problem solving ability greatly develops in this time period ${ }^{(2)}$. Hence considerable attention should be given by the psychologists on the events of first 4 - 5 years of childhood. If we know the answer of whether there has any medium-term effect of early life weather shock on children's intelligence level, the policy makers will be aware about the effect of cyclone on children's psychological development specially on intelligence.

The aim of the present study was to investigate the medium-term effect of weather shock on non-verbal intelligence among SIDR affected children.

\section{Materials and Methods}

A total of 60 children were selected as participants from 'Non-affected' and 'Affected' area. Barguna Sadar Upazila was selected as the highly SIDR affected area on the basis of damages and losses and Gazaria Upazila at Munshiganj district was selected as not SIDR affected area as the geographical characteristics of both areas were almost same. Firstly, two primary schools (up to grade 5) were selected through 'purposive sampling' from these two areas secondly, 30 students were selected from each school through 'systematic random sampling' (Students lists were collected from purposively selected school database and then participants were assigned and selected through computer based systematically randomized roll numbers). In this study, we used 'Quasi-experimental study design' (As we could not manipulate this naturally occurring condition, we administered this test in a controlled classroom set up. At the same time, we could control (balancing and consistency) some potential extraneous variables such as noise, light, gender of the participants etc.). Data were collected from January, 2012 to December, 2012 (after 5 years of SIDR). During SIDR, children age was ranged from 3 - 5 years and during current study, their age are ranging from $10-12$ years. Details about socio-demographic information are presented in Table 1. 
Table 1. Socio-demographic characteristics of the participants.

\begin{tabular}{lll}
\hline $\begin{array}{l}\text { Socio-demographic } \\
\text { characteristics }\end{array}$ & $\begin{array}{l}\text { Non-affected group } \\
(\mathrm{n}=30)\end{array}$ & $\begin{array}{l}\text { Affected group } \\
(\mathrm{n}=30)\end{array}$ \\
\hline Age & $\overline{\mathrm{x}}=11.23$ & $\overline{\mathrm{x}}=11.48$ \\
$\mathrm{Sd}=1.02$ & $\mathrm{Sd}=1.74$ \\
\hline Gender & Male $=15$ & Male $=16$ \\
& Female $=15$ & Female $=14$ \\
\hline Grade & Grade four $=17$ & Grade four $=11$ \\
& Grade five $=13$ & Grade five $=19$ \\
\hline Father's occupation & Farmer $=9$ & Farmer $=12$ \\
& Labor $=9$ & Labor $=6$ \\
& Businessman $=6$ & Businessman $=4$ \\
& Fisherman $=3$ & Employee $=4$ \\
& Employee $=2$ & Immigrate $=3$ \\
& Immigrate $=1$ & Fisherman $=1$ \\
\hline
\end{tabular}

$\mathrm{N}=60$.

In this study, the following instruments were used.

Personal Information Form (PIF): This section contains the respondents' demographical information such as age, gender, grade, date of birth, father's occupation, father's education level.

Test of Nonverbal Intelligence - Second Edition (TONI-2): TONI-2 was developed by Brown et al.(23). It is a culturally-fair, language-free as well as motor reduced measure of IQ on 5 to 80 years of age. It contains two equivalent forms (Form A and form B) of the test containing 55 items each. Here, Form A was selected for the current study. All of the items require abstract/figure based problem solving. Participants look at the stimulus items and responds by means of pointing or other meaningful motor activity. This test is highly reliable. Average Cronbach's coefficient alpha for Form A and Form B were .95 and 0.96 , respectively, test re-test reliability ranged from 0.50 to $0.80 \mathrm{~s}$ and split-half reliability was $0.90 \mathrm{~s}^{(23)}$. Validity evidence proposes the best interpretive score being the overall Non-verbal Intelligence Quotient (NVIQ). In case of content validity studies, the test is good enough in terms of little-to-no bias seen between gender, age, ethnic background groups. Concurrent validity of this test is also adequate enough compared to the most popular IQ test such as the Wechsler scales(23).

Scoring: At first a basal point has to be detected through respondent's five consecutive correct responses. The lasthighest numbered of those five correct item would be considered as that respondent's basal item. Ceiling item can be found when a respondent make three errors within five consecutive items. The ceiling item is the last / highest numbered of the three errors. Finally, the total score can be found through summing up basal item's number and correct response(s) between basal item and ceiling 
item. The summed total raw scores are then converted into final IQ scores by following corresponding norm table of TONI-2. The final IQ scores can be classified into five groups on the basis of score ranges such as 'Above Average' ( $\geq 110)$, 'Average' (90-109), 'Below Average' (80-89), 'Poor' (70-79) and 'Very Poor' ( $\leq 69)^{(23)}$.

First of all SIDR affected area, Barguna Sadar Upazila was selected through 'purposive sampling technique' among the Upozillas of highly SIDR affected districts. At the same time, Non SIDR affected area Gajaria was conveniently selected, which is geographically very similar to Barguna. One school was selected from each Upazila, after than 30 students were selected from each school through 'systematic random sampling technique'. A controlled class room setup (clam atmosphere, adequate lightning system, room only occupied with research materials such as black screen, test booklet, setting arrangements, data recording material) was arranged for administering this test. The TONI-2 was individually administered (one to one basis). Each subject was given verbal instruction for easy understanding. There were six trial items before starting the main test. After completing the trial items participants performed the main task items. After presenting each item response was noted in record form. The same procedure was followed for both groups. After completing the task successfully, each respondent left the classroom. Total test administration took approximately $15-20$ minutes.

\section{Results and Discussion}

Here, Table 2 indicates the non-verbal intelligence (IQ) of SIDR affected children is significantly lower than the non-verbal intelligence (IQ) of non-affected participants. Mean of IQ reveals that the TONI-2 IQ of affected participants was significantly lower (78.6 \pm 9.87$)$ than non-affected participants $(90.57 \pm 8.827)$.

Table 2. Comparison of SIDR affected and non-affected children's non-verbal intelligence score within the TONI-2 Test.

\begin{tabular}{lcccc}
\hline Affectedness & $\bar{x}$ & Sd & $t$ & Sig. (2-tailed) \\
\hline Non-affected Group & 90.57 & 8.827 & $4.950^{* *}$ & 0.006 \\
Affected Group & 78.6 & 9.87 & & \\
\hline
\end{tabular}

$\mathrm{N}=60, \mathrm{df}=58$ and ${ }^{* *} \mathrm{p}<0.01$.

In Fig. 1, we found that there are significant differences between SIDR 'affected' and 'non-affected' children's non-verbal intelligence (IQ score) categories $\left(\lambda^{2}=21.29, \mathrm{p}<0.05\right)$ (Table not shown). On the basis of five IQ categories, it can be noticed that SIDR nonaffected children's IQ score is always higher than the SIDR affected children's IQ Score. 


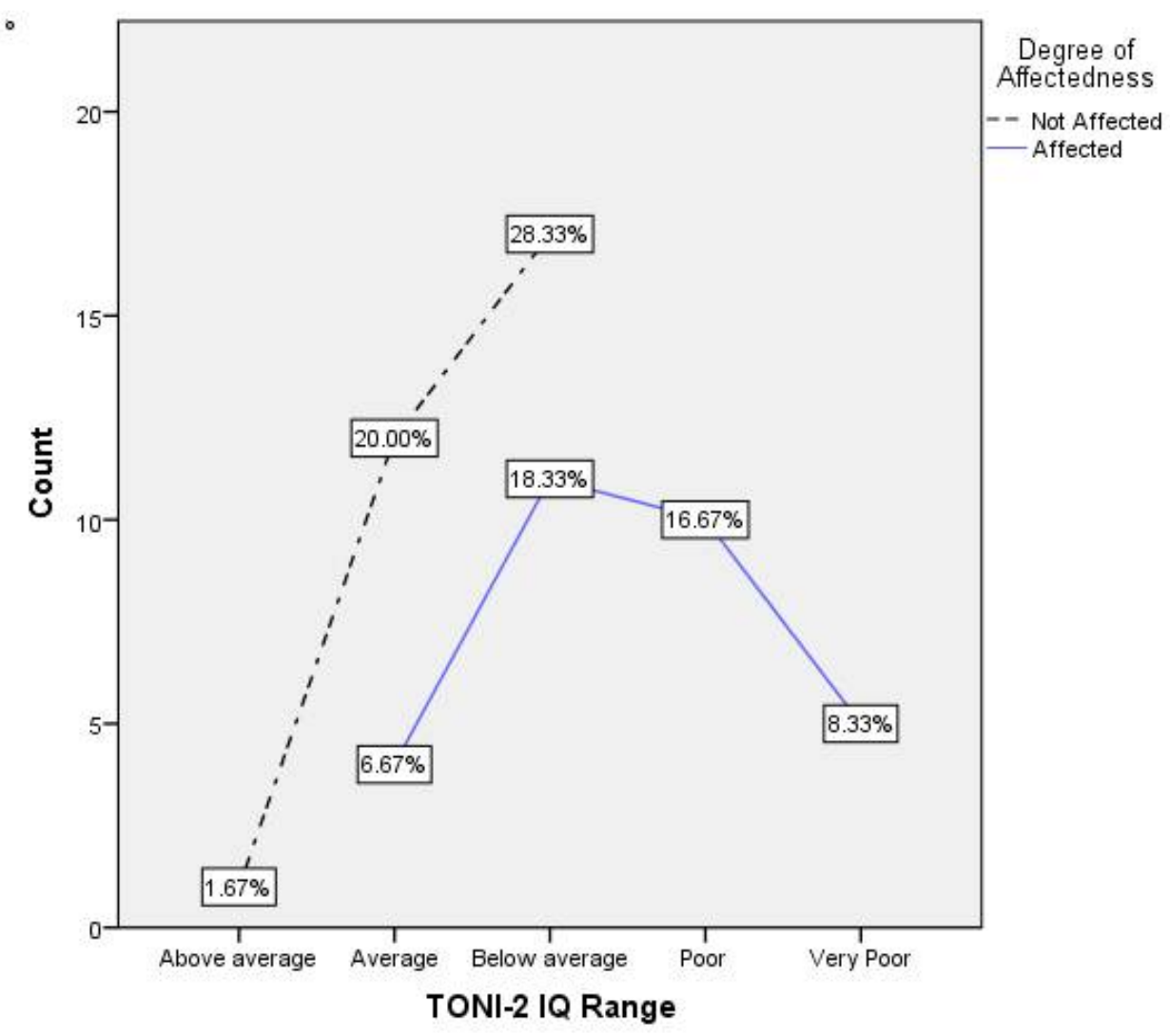

Fig. 1. SIDR affected and non-affected groups' difference in IQ range category.

The research was intended to investigate the medium-term effect of early life weather shock on non-verbal intelligence of SIDR affected children. On the beam of earlier evidences it was hypothesized that the IQ of SIDR affected children would be lower than the IQ of SIDR non-affected children. To administer the study 'two independent groups Quasi-experimental design' was followed. TONI-2 was employed to measure the non-verbal intelligence of children. Furthermore, independent sample t-test was applied to analyze data. Here, Table 3.1 indicates that nonverbal intelligence of affected participants are significantly lower $(78.6 \pm 9.87)$ than non-affected participants $(90.57 \pm 8.827)$ (Table 1). This finding supports already existing findings ${ }^{(13,16)}$. Children's parents' socioeconomic status ${ }^{(22)}$ and malnutrition(24) are important correlates of children's IQ. While, no acute malnutrition were reported(12), to analyze the household income, socioeconomic status, education level as well as occupation could be studied(25). In this study, father's occupation was taken as a measure of socioeconomic status which does not show any significant difference between two groups (where $\lambda^{2}=6.914$ with $\mathrm{df}=6)$. 
Early childhood ranged from birth to five years while complex social behaviors, problem-solving abilities and emotional capacities are increasingly emerging(2). Traumatic events or experiences during first five years of life create intense effect on problem-solving abilities ${ }^{(2)}$. Prolonged exposure of disturbing life experiences (including weather shock) during this early stage hamper their mental development ${ }^{(26)}$ and make them more vulnerable to stress which can lead to impaired brain development ${ }^{(27)}$. Previous evidences are evident for the effect of early life malnutrition, moderate and severe stunting, under weight ${ }^{(24)}$, exposure to violence and trauma-related distresses ${ }^{(28)}$ on cognitive abilities such as IQ and educational outcomes.

Due to the geographical location, Bangladesh is a disaster prone country ${ }^{(12)}$. The worst sufferer people not only lost their family, home and property but also psychologically disturbed which can be the cause of nervous breakdown and posttraumatic stress disorder(29). The post SIDR intervention, Cash-for-Work (CFW) and provision of food aid programs were introduced to defend a sustenance crisis as a result malnutrition or distress sales of remaining household asset was tackled ${ }^{(12)}$, this provision of food aid and Cash-for-Work programs could be more effective in reducing impacts of SIDR on children.

From this study finding, it is evident that early life weather shock (SIDR) has a significant medium term effect on non-verbal intelligence. Engle et al.(30) stated that psychosocial interventions are simultaneously as effective as mitigation strategy following any natural calamities (weather shock). So, psycho-social intervention is very crucial just after such weather shock to minimize such medium term adverse impact (30).

This study was the first attempts to assess medium-term effect of cyclone on children's non-verbal intelligence in Bangladesh. For constraints of time and budget, there were some limitations such as we could not randomly select the affected area. Degree of affectedness should be statistically determined from damages and losses.

\section{References}

1. Mattocks C, A Ness, K Deere, K Tilling, S Leary, SN Blair and C Riddoch 2008. Early life determinants of physical activity in 11 to 12 year olds: cohort study. Bmj 336(7634): 26-29.

2. Garner AS, JP Shonkoff, BS Siegel, MI Dobbins, MF Earls, L Mc Guinn and Committee on Early Childhood, Adoption, and Dependent Care 2012. Early childhood adversity, toxic stress, and the role of the pediatrician: translating developmental science into lifelong health. Pediatrics 129(1): e224-e231.

3. Brown L, RJ Sherbenou and SK Johnsen 1990. TONI-2: Test of nonverbal intelligence: A language-free measure of cognitive ability. Pro-Ed.

4. Breslau N, EO Johnson and VC Lucia 2001. Academic achievement of low birth weight children at age 11: The role of cognitive abilities at school entry. Journal of Abnormal Child Psychology 29(4): 273-279. 
5. United Nations Office for Disaster Risk Reduction (UNISDR) 2011. UNISDR says the young are the largest group affected by disasters. Brussels, Belgium. Retrieved from http://www.unisdr.org /archive/22742.

6. U. S. Global Change Research Program 2016. The impacts of climate change on human health in the United States: A scientific assessment. Washington, DC.

7. McDermott B, V Cobham, H Berry and B Kim2014. Correlates of persisting posttraumatic symptoms in children and adolescents 18 months after a cyclone disaster. Australian \& New Zealand Journal of Psychiatry 48(1): 80-86.

8. Blaikie P, T Cannon, I Davis and B Wisner2014. At risk: natural hazards, people's vulnerability and disasters. Routledge.

9. Armsworth MW and M Holaday1993. The effects of psychological trauma on children and adolescents. Journal of Counseling \& Development 72(1): 49-56.

10. Irwin RJ 1984. Inspection time and its relation to intelligence. Intelligence 8(1): 47-65.

11. Baez JE and IV Santos2007. Children's vulnerability to weather shocks: A natural disaster as a natural experiment. Social Science Research Network, New York.

12. Government of Bangladesh 2008. Cyclone SIDR in Bangladesh: Damage, loss and needs assessment for disaster recovery and reconstruction.

13. Aguilar A and M Vicarelli 2011. El Nino and Mexican children: medium-term effects of early-life weather shocks on cognitive and health outcomes. Cambridge, United States: Harvard University, Department of Economics. Manuscript.

14. Johnson MH 2001. Functional brain development in humans. Nature Reviews Neuroscience 2(7): 475.

15. HeckmanJJ and T Kautz2013. Fostering and measuring skills: Interventions that improve character and cognition (No. w19656). National Bureau of Economic Research.

16. Masten AS and JD Coatsworth1998. The development of competence in favorable and unfavorable environments: Lessons from research on successful children. American Psychologist 53(2): 205.

17. Kendler KS and CA Prescott 2007. Genes, environment, and psychopathology: Understanding the causes of psychiatric and substance use disorders. Guilford Press.

18. Jensen A1969. How much can we boost IQ and scholastic achievement. Harvard Educational Review 39(1): 1-123.

19. Klebanov and K Pamela 1998. The contribution of neighborhood and family income to developmental test scores over the first three years of life. Child development 69(3): 1420-1436.

20. Neisser UE 1998. The rising curve: Long-term gains in IQ and related measures. American Psychological Association.

21. Saltzman KM, CF Weems and VG Carrion 2006. IQ and posttraumatic stress symptoms in children exposed to interpersonal violence. Child Psychiatry and Human Development 36(3): 261-272.

22. Hanscombe KB, M Trzaskowski, CM Haworth, OS Davis, PS Dale and R Plomin 2012. Socioeconomic status (SES) and children's intelligence (IQ): In a UK-representative sample SES moderates the environmental, not genetic, effect on IQ. PloS one 7(2): e30320.

23. Brown DW, RF Anda, H Tiemeier, VJ Felitti, VJ Edwards, JB Croft and WH Giles 2009. Adverse childhood experiences and the risk of premature mortality. American Journal of Preventive Medicine 37(5): 389-396. 
24. Glewwe P and EM King 2001. The impact of early childhood nutritional status on cognitive development: Does the timing of malnutrition matter? The World Bank Economic Review 15(1): 81-113.

25. Turkheimer E, A Haley, M Waldron, B d'Onofrio and II Gottesman 2003. Socioeconomic status modifies heritability of IQ in young children. Psychological Science 14(6): 623-628.

26. Haywood HC and JT Tapp1966. Experience and the development of adaptive behavior. In: International Review of Research in Mental Retardation 1: 109-151.

27. Oomen CA, H Soeters, N Audureau, L Vermunt, FN Van Hasselt, EM Manders and H Krugers 2010. Severe early life stress hampers spatial learning and neurogenesis, but improves hippocampal synaptic plasticity and emotional learning under high-stress conditions in adulthood. Journal of Neuroscience 30(19): 6635-6645.

28. Delaney-Black V, C Covington, SJ Ondersma, B Nordstrom-Klee, T Templin, J Ager and RJ Sokol 2002. Violence exposure, trauma, and IQ and/or reading deficits among urban children. Archives of Pediatrics \& Adolescent Medicine 156(3): 280-285.

29. Desjarlais R and L Eisenberg (Eds.) 1995. World mental health: Problems and priorities in low-income countries. Oxford University Press, USA.

30. Engle PL, MM Black, JR Behrman, MC De Mello, PJ Gertler, L Kapiriri and International Child Development Steering Group 2007. Strategies to avoid the loss of developmental potential in more than 200 million children in the developing world. The Lancet 369(9557): 229-242.

(Manuscript received on 15 March, 2018; revised on 14 October, 2018) 